\title{
Loss of Kv3.1 Tonotopicity and Alterations in cAMP Response Element-Binding Protein Signaling in Central Auditory Neurons of Hearing Impaired Mice
}

\author{
Christian A. A. von Hehn, ${ }^{\star}$ Arin Bhattacharjee, ${ }^{\star}$ and Leonard K. Kaczmarek \\ Department of Pharmacology, Yale University School of Medicine, New Haven, Connecticut, 06520
}

\begin{abstract}
The promoter for the $k v 3.1$ potassium channel gene is regulated by a $\mathrm{Ca}^{2+}-\mathrm{cAMP}$ responsive element, which binds the transcription factor cAMP response element-binding protein (CREB). Kv3.1 is expressed in a tonotopic gradient within the medial nucleus of the trapezoid body (MNTB) of the auditory brainstem, where Kv3.1 levels are highest at the medial end, which corresponds to high auditory frequencies. We have compared the levels of Kv3.1, CREB, and the phosphorylated form of CREB (pCREB) in a mouse strain that maintains good hearing throughout life, $\mathrm{CBA} / \mathrm{J}$ (CBA), with one that suffers early cochlear hair cell loss, C57BL/6 (BL/6). A gradient of Kv3.1 immunoreactivity in the MNTB was detected in both young ( 6 week) and older (8 month) CBA mice. Although no gradient of CREB was detected, pCREB-immunopositive cells were grouped together in distinct clusters along the tonotopic axis. The same pattern of Kv3.1, CREB, and pCREB localization was also found in young BL/6 mice at a time (6 weeks) when hearing is normal. In contrast, at 8 months, when hearing is impaired, the gradient of Kv3.1 was abolished. Moreover, in the older BL/6 mice there was a decrease in CREB expression along the tonotopic axis, and the pattern of pCREB labeling appeared random, with no discrete clusters of pCREB-positive cells along the tonotopic axis. Our findings are consistent with the hypothesis that ongoing activity in auditory brainstem neurons is necessary for the maintenance of Kv3.1 tonotopicity through the CREB pathway.
\end{abstract}

Key words: auditory; Kv3.1; MNTB; CREB; tonotopicity; presbyacusis

\section{Introduction}

Age-related hearing-loss (presbyacusis) is the most common cause of adult auditory deficiency in the United States. Although progressive loss of hair cell function is a main pathogenic factor, it is not clear whether presbyacusis involves only the dysfunction of sensory hair cells or whether there are also resultant changes in auditory neurons (Boettcher, 2002; Seidman et al., 2002). In the C57BL/6 (BL/6) mouse strain, loss of sensory hair cells begins during early adulthood, starting in the base of the cochlea and progressing toward the apex as aging continues (Spongr et al., 1997). In contrast, the CBA/J (CBA) mouse strain exhibits no significant cochlear pathology until relatively late in life. As a consequence, the comparison of BL/6 and CBA strains is often used as an experimental model for age-related and sensorineural hearing loss (Willott et al., 1992; McFadden et al., 2001; Willott, 2001; Prosen et al., 2003). Other mouse strains, such as the DBA/2J strain, also develop severe hearing deficits (Willott and Bross, 1996).

The first integration of binaural inputs occurs in the superior

\footnotetext{
Received 0ct. 7, 2003; revised Jan. 11, 2004; accepted Jan. 11, 2004.

This work was supported by National Institutes of Health Grants DC-01919 and NS42202 and by the American Federation for Aging Research. We thank U. Schulz and J. Hedderich for statistical advice.

${ }^{*}$ C.A.A.H. and A.B. contributed equally to this work.

Correspondence should be addressed to Leonard K. Kaczmarek, Department of Pharmacology, Yale University School of Medicine, 333 Cedar Street, New Haven, CT 06520. E-mail: leonard.kaczmarek@yale.edu. DOI:10.1523/JNEUROSCI.4554-03.2004

Copyright $\odot 2004$ Society for Neuroscience $\quad$ 0270-6474/04/241936-05\$15.00/0
}

olivary complex (SOC). Within the SOC, the medial nucleus of the trapezoid body (MNTB) functions as a fast sign-inverting relay station. Precisely timed inhibitory input from the MNTB to the medial and lateral superior olive is required for comparison of interaural time and level differences and therefore for sound localization (Grothe, 2003). Like most auditory nuclei, the MNTB is organized tonotopically, such that neurons located medially conduct information about higher frequencies, whereas laterally located neurons relay information on lower frequencies. Although the tonotopic organization of sensory hair cells is largely a result of the mechanical organization of the cochlea (Rubel and Fritzsch, 2002), it is not known how this organization is preserved in the CNS, nor is it known which proteins determine this tonotopic ordering. In chicks, however, it has been shown that the tonotopic organization of the nucleus magnocellularis, a nucleus with properties similar to the MNTB, is stimulus dependent (Cohen and Saunders, 1994).

The potassium channel Kv3.1 is generally expressed in neurons that are capable of firing action potentials at high rates. It is expressed at particularly high levels in the auditory brainstem, including the MNTB (Luneau et al., 1991; Perney et al., 1992; Weiser et al., 1995; Wang et al., 1998a; Grigg et al., 2000). Appropriately, Kv3.1 protein has been shown to be expressed tonotopically in rat MNTB (Li et al., 2001) and avian auditory nucleus magnocellularis (Parameshwaran-Iyer et al., 2001), with highest expression occurring in neurons at the high frequency end of the tonotopic axis. 
Kv3.1 is the only neuronal potassium channel for which transcription is known to be regulated by the $\mathrm{CA}^{2+}-$ cAMPresponsive element binding protein (CREB) transcription factor (Gan et al., 1996; Lonze and Ginty, 2002). Moreover, the expression of this potassium channel in the inferior colliculus has been shown to be regulated by depolarization (Liu and Kaczmarek, 1998). CREB is perhaps the best-characterized transcription factor that is activated by external stimulation of a cell. All signaling pathways that activate CREB lead to phosphorylation of the protein at serine 133 (Ser133) (Shaywitz and Greenberg 1999; Lonze and Ginty, 2002). It has been shown previously that the phosphorylational state of CREB in the auditory brainstem can be modulated through changes in cochlear input (Illing et al., 2002).

In this study we have examined the localization of Kv3.1, CREB, and the phosphorylated form of CREB (pCREB) in normal-hearing CBA mice at both 6 weeks and 8 months of age, and in BL/6 mice at the same stages. At 6 weeks the hearing of $\mathrm{BL} / 6$ mice is apparently normal, whereas at 8 months hearing is clearly impaired (Parham and Willott, 1988; Spongr et al., 1997; McFadden et al., 2001).

\section{Materials and Methods}

Six-week- and 8-month-old CBA/J and C57BL/6 and 8-month-old $\mathrm{DBA} / 2 \mathrm{~J}$ male mice were tested for auditory impairment with a startle test (Parham and Willott, 1988). All groups of mice reacted strongly to a loud acoustic stimulus with the exception of the 8-month-old C57BL/6 and the 8-month-old DBA/2J animals, which showed little or no response. Immunohistochemistry was performed as described previously (Bhattacharjee et al., 2002). Anti-CREB and anti-pCREB were purchased from Cell Signaling Technology (Beverly, MA). The antibody dilution for CREB and pCREB was 1:100 as per manufacturer's guidelines. For the anti-Kv3.1 antibody, the dilution was 1:500 as described previously (Perney and Kaczmarek, 1997).

All pictures were taken on an Olympus BX60 microscope by using a SPOT RT digital camera (Diagnostic Instruments, Sterling Heights, MI). Optical density (OD) and integrated optical density (IOD) were measured using ImagePro Plus software (Media Cybernetics, Silver Spring, MD). For CREB and pCREB, the software automatically determined nuclear staining. For Kv3.1, the outline of each cell was drawn manually, and the maximal optical density was measured. Where appropriate, the relative optical density was calculated by normalizing all obtained optical densities on a section to the highest density on the section.

\section{Results}

In coronal sections of the brainstem, neurons within the MNTB are organized tonotopically, with low-frequency neurons located laterally and high-frequency neurons located medially (Sommer et al., 1993; Ehret and Romand, 1997). Mice with functional hearing, namely young CBAs, old CBAs, and young BL/6, show a clear tonotopic distribution of Kv3.1 expression over the medial-lateral axis of the MNTB (Fig. 1). Highest levels of Kv3.1 are detected at the medial, high-frequency end of the nucleus. These results are consistent with what has been reported previously for the MNTB of the rat, which has no auditory dysfunction (Li et al., 2001). The tonotopic gradient of Kv3.1 was absent, however, in hearing-impaired mice (old BL/6 and DBA/2J), in which uniform staining for Kv3.1 was found within the MNTB (Fig. 1, bottom panel). It should be noted that Kv3.1 immunoreactivity was not absent in the older BL/ 6 animals but that the staining, as determined by densitometry, remained constant over the tonotopic axis, with slopes not differing significantly from zero (Fig. 1, bottom panel). Because Kv3.1 channels are present in both presynaptic terminals and somata within the MNTB (Wang et al., 1998 b), the decrease in levels of Kv3.1 protein within auditory
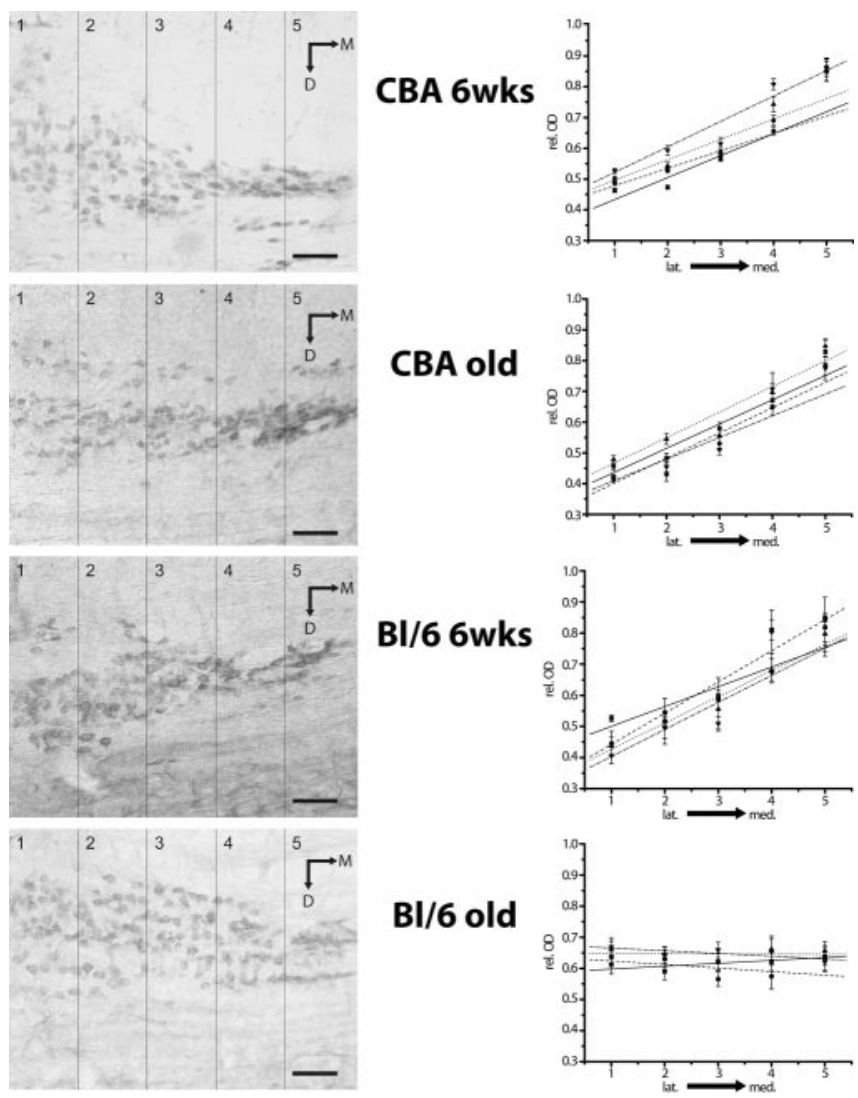

Figure 1. Quantification of tonotopic gradient of Kv3.1 in the MNTB. Left, Coronal sections of the MNTB of (BAs and BL/ 6 mice ( 6 weeks and 8 months). Right, Four individual sections for each strain and age group were divided in five equal segments from lateral to medial. The mean Kv3.1 OD of all cells within each segment was measured and normalized to the darkest cell in each section. The gradient of Kv3.1 immunoreactivity is clear in all sections ( $p<0.05)$, except for old BL/6 mice. The data are representative of four animals for each age group and strain. Lines through data show results of regression analysis; $R$ values for sections from young CBA: $0.9142,0.90744,0.94096,0.96983 ; R$ values for sections from old CBA: $0.96237,0.96336$, $0.96249,0.93388 ; R$ values for sections from young $B L / 6: 0.97647,0.97202,0.98277,0.82361$; $R$ values for sections from old $\mathrm{BL} / 6: 0.77473,-0.43453,-0.05161,-0.7349$. Scale bar, 250 $\mu \mathrm{m}$. A tonotopic gradient in Kv3.1 immunoreactivity was also absent in 8-month-old DBA/2J mice, which are hearing impaired (data not shown).

brainstem neurons of the older BL/6 mice is likely to represent changes in both compartments.

The $k v 3.1$ gene is regulated by CREB and by depolarization (Gan et al., 1996; Liu and Kaczmarek, 1998). We therefore determined whether CREB itself is distributed tonotopically within the MNTB and whether CREB expression is attenuated in hearingimpaired mice. By sectioning and staining in the same manner as for $\mathrm{Kv} 3.1$, we found that there is no significant gradient of CREB across the tonotopic axis of the MNTB (Fig. 2A,B). Nevertheless, there was a significant difference in CREB immunoreactivity between the hearing and hearing-impaired mice (Fig. $2 B, C$ ). CREB immunoreactivity was almost $50 \%$ lower in old BL/6 mice compared with CBA mice of the same age (Fig. $2 A-C$ ). The decreased immunoreactivity was detected over the entire tonotopic axis (Fig. 2A,B). We found a similar decrease in CREB immunoreactivity in the ventral cochlear nucleus (VCN), which provides afferent input to the principal cells of the MNTB. In contrast, we found no differences in CREB immunoreactivity between young $\mathrm{BL} / 6$ and CBA animals (data not shown).

As a control for this difference in CREB staining between the 8-month-old BL/6 and CBA mice, we also analyzed CREB stain- 
A

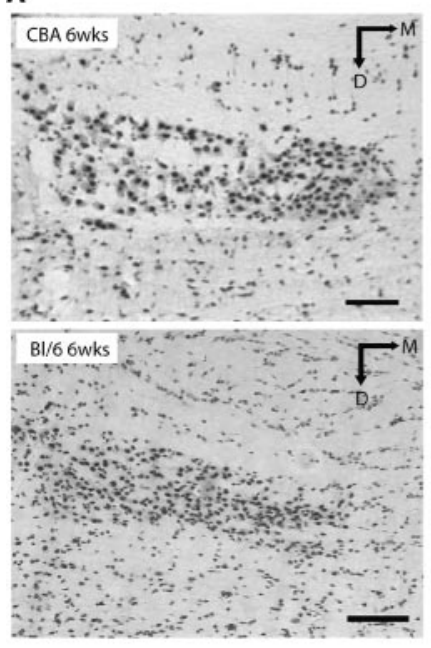

B

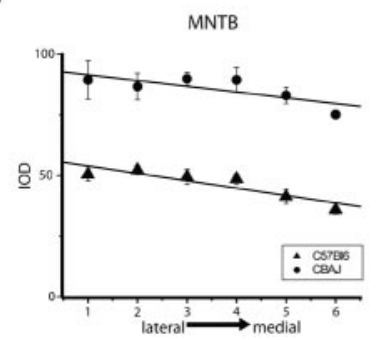

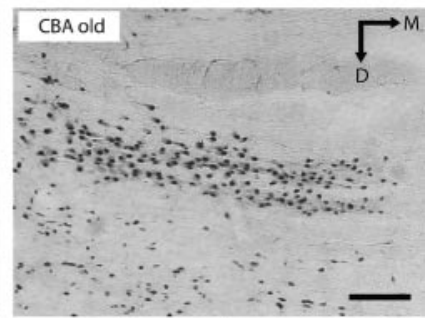

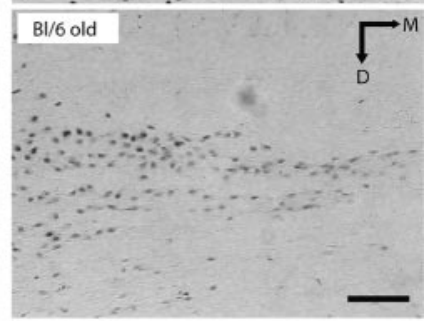

C

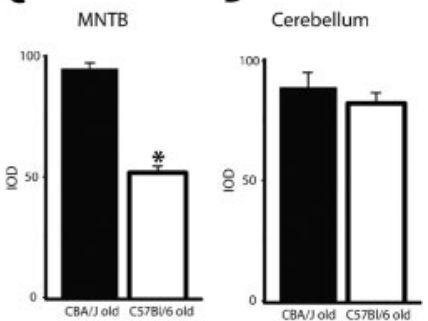

Figure 2. CREB immunoreactivity in the MNTB and the cerebellum. $A$, Examples of four MNTB sections from each strain and age group. $B$, The MNTB was divided into six equal segments from lateral to medial. The IOD was measured for individual cells of each section. Lines through data show results of regression analysis. Comparing the two strains, from lateral to medial, no tonotopic increase of CREB immunoreactivity was found. Slopes of both lines did not significantly differ from zero; $R$ value for old CBA: $-0.77121 ; R$ value for old $B L / 6-0.89616$. C, There was a $\sim 50 \%$ decrease, however, of total CREB immunoreactivity in the MNTB of BL/6 compared with CBA. D, Using the same sections containing the MNTB, we also examined cerebellar Purkinje cells of both strains; there was no significant difference in IOD between the two strains. $n=5$ for both strains; error bars represent SEM; ${ }^{*} p<0.05$ determined by unpaired $t$ test. Scale bar, $250 \mu \mathrm{m}$.

ing in the cerebella of the two species. Such staining would not be expected to be influenced by changes in auditory function. In coronal sections of the mouse brainstem, the MNTB and parts of the cerebellum are located on the same slice (Franklin and Paxinos, 1997) and therefore are stained in exactly the same way. No differences in CREB immunoreactivity could be found in the Purkinje cells of old CBA and old BL/6 mice (Fig. 2D). These results strongly suggest that the difference in CREB staining for the MNTB was a feature inherent to the MNTB and not caused by a variation of staining from section to section.

Because CREB is only active as a transcription factor when it is phosphorylated, we investigated the distribution of activated pCREB by staining sections of the MNTB with a CREB-Ser133 phospho-specific antibody. Interestingly, in mice with intact audition (6-week- and 8-month-old CBA, 6-week-old BL/6), we found a pattern that differed from mouse to mouse. Like CREB itself, the staining for pCREB was confined to the nucleus. Nevertheless, only subsets of neurons were labeled with the pCREB antibody, whereas others appeared devoid of labeling. Strikingly, labeled neurons were always grouped into discrete clusters, which were distributed along the tonotopic axis in each section (Fig. 3).

To quantify the clustering along the tonotopic axis, we first established that pCREB labeling was binary, i.e., that a given neu-
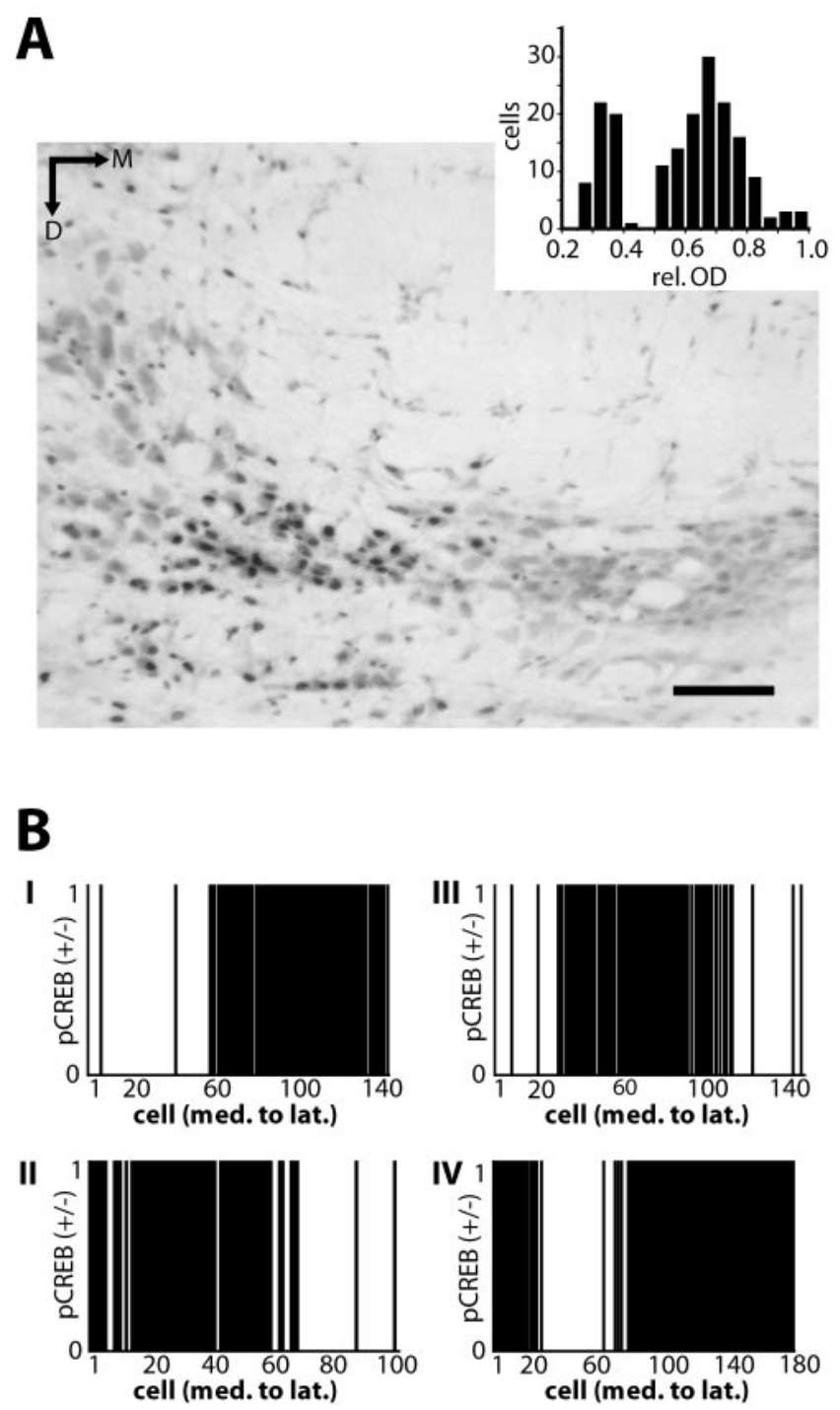

Figure 3. $\quad \mathrm{pCREB}$ immunoreactivity in MNTB of old CBAs. $A$, Example of a coronal MNTB section of an 8-month-old CBA stained for pCREB. Inset, Density distribution histogram demonstrating the bimodality of $p C R E B$ staining. $B$, Optical densities over nuclei from all cells within four individual MNTBs were counted across the medial-lateral axis. Cells with a relative $p C R E B$ $O D>0.5$ were assigned 1 ; cells with a relative $P C R E B O D<0.4$ were assigned 0 . The data are representative of five animals for each age group. Scale bar, $250 \mu \mathrm{m}$.

ron could be uniquely assigned as PCREB positive or pCREB negative. The distribution of densities detected in neurons stained for pCREB was found to be clearly bimodal (Figs. $3 A$, insert, $4 A$, insert), with the peak of the lower density corresponding to unstained nuclei. As a result, it is possible to give each neuron a score of " 1 " for a stained nucleus and " 0 " for an unstained nucleus (Figs. 3, 4). Figure 3 illustrates the clustering of pCREB staining along the medial to lateral axis in the form of a "bar code" for four different MNTBs of normal-hearing old CBAs. To quantify the pattern of clustering of pCREB staining we used the Runs test for detecting non-randomness and obtained $p$ values $(<0.0001)$ for all sections, indicating that these sequences are significantly different from a random distribution of staining.

In contrast to the normal-hearing animals, pCREB labeling in the hearing-impaired BL/6 and DBA/2J mice provided no evidence of clusters along the medial-lateral axis. Instead, staining appeared to be randomly distributed over the tonotopic axis of the MNTB, as revealed by a comparison of the barcodes for these 


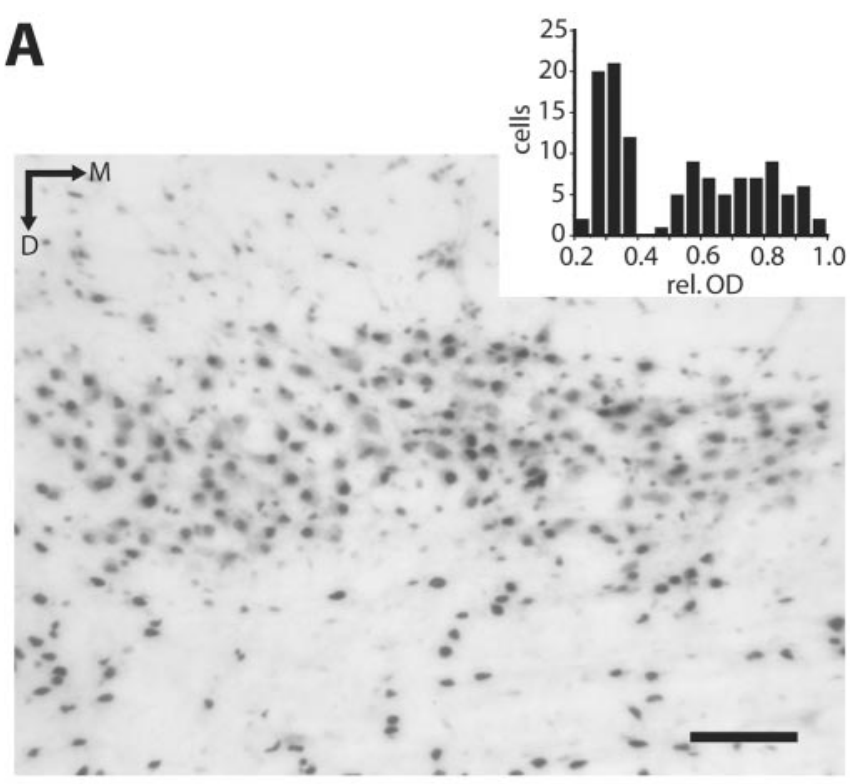

B
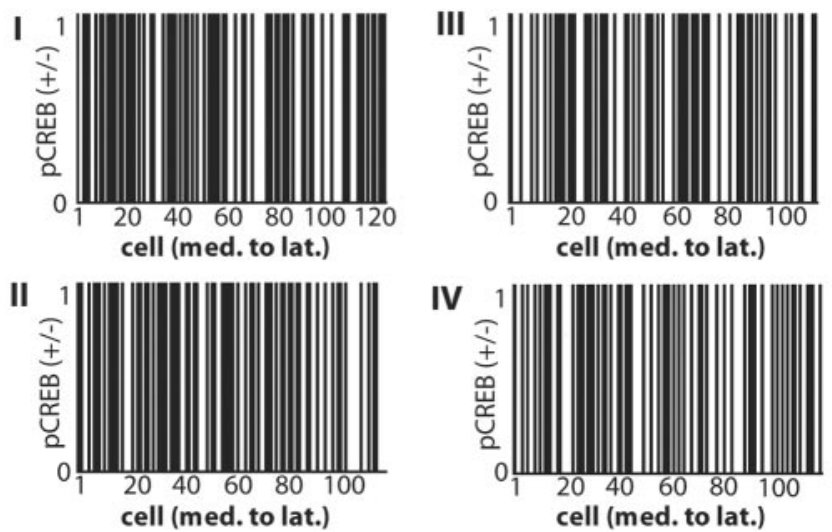

Figure 4. $\quad \mathrm{pCREB}$ immunoreactivity in MNTB of old BL/6 mice. $A$, Example of a coronal MNTB section of an 8-month-old BL/6 stained for pCREB. Inset, Density distribution histogram demonstrating the bimodality of $\mathrm{pCREB}$ staining. $B$, The optical densities over nuclei from all cells within four individual MNTBs were counted across the medial-lateral axis. Cells with a relative $\mathrm{pCREB} 0 \mathrm{D}>0.5$ were assigned 1 ; cells with a relative $\mathrm{pCREB} 0 \mathrm{D}<0.4$ were assigned 0 . The data are representative of four animals for each age group. Scale bar, $250 \mu \mathrm{m}$. A similar pattern of pCREB immunoreactivity was found in hearing-impaired DBA/2J mice (data not shown).

animals (Fig. 4). Defining a cluster as one or more adjacent stained cells, we found that the pattern of pCREB staining of hearing-impaired animals was significantly different from that of the hearing mice (mean cluster size CBA: $9.13 \pm 2.98$ (SEM) cells; mean cluster size BL/6: $1.77 \pm 0.08$ cells; $p<0.0001)$.

As shown here for the MNTB, pCREB labeling in the VCN of normal-hearing CBA and 6-week-old BL/6 mice also revealed discrete clusters of staining, and again in 8-month-old BL/6 mice, pCREB staining appeared to be distributed randomly in the VCN (data not shown).

\section{Discussion}

We have found that a tonotopic gradient of Kv3.1 expression in the MNTB is present in young $\mathrm{BL} / 6$ mice when their hearing is normal but that the gradient is lost later in life when hearing is impaired. The loss of the gradient is accompanied by a decrease in CREB and a change in the distribution of PCREB, the activated, phosphorylated transcription factor. In particular, the deficit in hearing is associated with the loss of discrete clusters of pCREBpositive cells along the tonotopic axis. In contrast, in the CBA mouse species, which maintains good hearing throughout its life, the tonotopic gradient of Kv3.1 and the localization of pCREB to discrete cell clusters in the MNTB are maintained through adulthood. Although loss of sensory input is associated with a small loss of neurons in some central nuclei (Willott and Bross, 1996), our measurements were made on stained cells with intact nuclei and normal morphology, indicating that the changes in the distribution of Kv3.1 and CREB result from altered expression and are not secondary to any change in cell number.

The genetic basis for the loss of cochlear hair cells in BL/6 mice is thought to be caused by a genetic defect of the cdh 23 gene (Noben-Trauth et al., 2003). If this defect is confined to hair cells, our work strongly suggests that a normal ongoing pattern of auditory stimulation in the auditory brainstem is required for maintenance of expression of the transcription factor CREB, its state of phosphorylation, and the tonotopic gradient of the potassium channel Kv3.1. Other ion channels (e.g., Kv1 and Kv3) are also expressed in the auditory brainstem (Ishikawa et al., 2003). Inspection of the upstream regions for these channel genes, however, indicates that there are no CRE consensus sites in the promoter regions. This suggests that these channels are not directly regulated by CREB, although their expression could be regulated by activity through other transcription factors.

Because the transcription of the Kv3.1 is regulated by CREB (Gan et al., 1996), it is likely that the altered pattern of CREB phosphorylation contributes directly to the loss of the gradient in $\mathrm{Kv} 3.1$ expression in the 8-month-old BL/6 animals. In particular, deletion of the CRE from the Kv3.1 promoter does not influence basal transcription of the Kv3.1 gene but prevents the stimulation of transcription by the CREB pathway (Gan et al., 1996). It is very likely, however, that other factors must also contribute to the establishment of the Kv3.1 gradient. For example, the gene for CREB itself has a CRE and is regulated by CRE in its promoter (Meyer et al., 1993; Coven et al., 1998) but is not distributed tonotopically in the MNTB. One difference between the promoters of Kv3.1 and CREB is that the Kv3.1 promoter has an ap- 1 site (Meyer et al., 1993; Gan et al., 1996). The transcription factor AP-1 is not a single transcription factor but instead a series of related dimeric complexes of Fos and Jun (Wisdom, 1999). The immediate early genes $c$-fos and junD are also known to have CREs in their promoters (Lonze and Ginty, 2002). It is possible therefore that the interplay of CREB and AP-1 contributes to maintaining the tonotopic gradient during normal activity.

A decrease in Kv3.1 levels would be expected to compromise the ability of auditory neurons to maintain temporal precision at high rates of stimulation. In brain slice preparations, MNTB neurons lock their action potentials to imposed stimuli at frequencies of up to 600 $\mathrm{Hz}$ (von Gersdorff and Borst, 2002; Macica et al., 2003). In contrast, deletion of the $k v 3.1$ gene in mice impairs the ability of MNTB neurons in slices to follow imposed frequencies greater than $\sim 200$ $\mathrm{Hz}$ (Macica et al., 2003). Moreover it is not necessary for neurons to fire at such frequencies for a deficit to be apparent. Loss of the ability to fire at high frequencies is associated with a failure to respond accurately with high temporal resolution to even a pair of stimuli that are closely spaced in time (Macica et al., 2003). If Kv3.1 levels and tonotopicity are regulated by ongoing activity in auditory pathways, it is possible that a decrease in Kv3.1 levels in auditory brainstem neurons also occurs in human presbyacusis, where the hearing impairment is especially dominant at higher frequencies (Seidman et al., 2002). Age-related hearing loss is associated with poor speech 
discrimination and sound localization, particularly in the presence of background noise.

We have found that pCREB-immunopositive cells are distributed in clusters of cells within relatively broad frequency bands along the tonotopic axis of the MNTB. One of the most common stimuli leading to CREB phosphorylation in neurons is $\mathrm{Ca}^{2+}$ influx through voltage-dependent channels activated by neuronal firing, and even short bursts of action potentials have been found to activate CREB phosphorylation (Bonni et al., 1995; Chawla et al., 1998). The clusters within the bar codes of pCREB staining in the MNTB of normal hearing mice could therefore represent selective staining of neurons that were active before the nervous system was fixed. Within the MNTB and the VCN, neurons in close proximity to each other have overlapping tuning curves, and location of the clusters along the tonotopic axis may therefore correspond to sound frequencies that were most represented in some period of time before they were "frozen" onto the tonotopic axis of the MNTB. Phosphorylation of CREB at Ser133, however, is necessary but not sufficient to achieve transcription in activated neurons (Bito et al., 1996; Lonze and Ginty, 2002). In particular, activation of $k v 3.1$ transcription may require phosphorylation to be maintained for a specific duration or may also require additional changes in neuronal activity or activation of second messenger pathways. Nevertheless the disruption of the characteristic clusters of pCREB staining in the older hearingimpaired BL/ 6 mice suggests that the normal pattern of activity that sustains transcription of the $k v 3.1$ gene is disrupted.

\section{References}

Bhattacharjee A, Gan L, Kaczmarek LK (2002) Localization of the slack potassium channel in the rat central nervous system. J Comp Neurol 454:241-254.

Bito H, Deisserroth K, Tsien RW (1996) CREB phosphorylation and dephosphorylation: a $\mathrm{Ca}^{2+}$ - and stimulus duration-dependent switch for hippocampal gene expression. Cell 87:1203-1214.

Boettcher FA (2002) Presbyacusis and the auditory brainstem response. J Speech Lang Hear Res 45:1249-1261.

Bonni A, Ginty DD, Dudek H, Greenberg ME (1995) Serine 133phosphorylated CREB induces transcription via a cooperative mechanism that may confer specificity to neurotrophin signals. Mol Cell Neurosci 6:168-183.

Chawla S, Hardingham GE, Quinn DR, Bading H (1998) CBP: a signalregulated transcriptional coactivator controlled by nuclear calcium and CaM kinase IV. Science 281:959-963.

Cohen YE, Saunders JC (1994) The effect of acoustic overexposure on the tonotopic organization of the nucleus magnocellularis. Hear Res 81:11-21.

Coven E, Ni Y, Widnell KL, Chen J, Walker, Habener JF, Nestler EJ (1998) Cell type-specific regulation of CREB gene expression: mutational analysis of CREB promotor activity. J Neurochem 71:1865-1874.

Ehret G, Romand R (1997) The central auditory system. New York: Oxford UP.

Franklin KBJ, Paxinos G (1997) The mouse brain atlas in stereotaxic coordinates. San Diego: Academic.

Gan L, Perney TM, Kaczmarek LK (1996) Cloning and characterization of the promoter for a potassium channel expressed in high frequency firing neurons. J Biol Chem 271:5859-5865.

Grigg JJ, Brew HM, Tempel BL (2000) Differential expression of voltagegated potassium channel genes in auditory nuclei of the mouse brainstem. Hear Res 140:77-90.

Grothe B (2003) New roles for synaptic inhibition in sound localization. Nat Rev Neurosci 4:1-11.

Illing RB, Steffen SA, Kraus KS, Laszig R (2002) Transcription factor modulation and expression in the rat auditory brainstem following electrical intracochlear stimulation. Exp Neurol 175:226-244.

Ishikawa T, Nakamura Y, Saitoh N, Li W, Iwasaki S, Takahashi T (2003) Distinct roles of Kv1 and Kv3 potassium channels at the calyx of Held presynaptic terminal. J Neurosci 23:10445-10453.

Li W, Kaczmarek LK, Perney TM (2001) Expression of two high threshold potassium channels in the ascending nuclei of the rat auditory system. J Comp Neurol 437:196-218.

Liu SJ, Kaczmarek LK (1998) Depolarization selectively increases the expression of the Kv3.1 potassium channel in developing inferior colliculus neurons. J Neurosci 18:8758-8769.

Lonze BE, Ginty DD (2002) Function and regulation of CREB family transcription factors in the nervous system. Neuron 35:605-623.

Luneau CJ, Williams JB, Marshall J, Levitan ES, Oliva C, Smith JS, Antanavage J, Folander K, Stein RB, Swanson R, Kaczmarek LK, Buhrow SA (1991) Alternative splicing contributes to $\mathrm{K}^{+}$channel diversity in mammalian central nervous system. Proc Natl Acad Sci USA 88:3932-3936.

Macica CM, von Hehn CAA, Wang LY, Ho CS, Yokoyama S, Joho RH, Kaczmarek LK (2003) Modulation of the Kv3.1b potassium channel isoform adjusts the fidelity of firing patterns of auditory neurons. J Neurosci 23:1133-1141.

McFadden SL, Ding D, Salvi R (2001) Anatomical, metabolic and genetic aspects of age-related hearing loss in mice. Audiology 40:313-321.

Meyer TE, Waeber G, Lin J, Beckmann W, Habener JF (1993) The promotor of the gene encoding $3^{\prime}, 5^{\prime}$-cyclic adenosine monophosphate (cAMP) response element binding protein contains cAMP response elements: evidence for positive autoregulation of gene transcription. Endocrinology 132:770-780

Noben-Trauth K, Zheng QY, Johnson KR (2003) Association of cadherin 23 with polygenic inheritance and genetic modification of sensorineural hearing loss. Nat Genet 35:21-23.

Parameshwaran-Iyer S, Carr CE, Perney TM (2001) Expression of the Kv3.1 potassium channel in the avian auditory brainstem. J Neurosci 21:485-494.

Parham K, Willott JF (1988) Acoustic startle response in young and aging C57BL/6J and CBA/J mice. Behav Neurosci 102:881-886.

Perney TM, Kaczmarek LK (1997) Localization of a high threshold potassium channel in the rat cochlear nucleus. J Comp Neurol 386:178-202.

Perney TM, Marshall J, Martin KA, Hockfield S, Kaczmarek LK (1992) Expression of the mRNAs for the Kv3.1 potassium channel gene in the adult and developing rat brain. J Neurophysiol 68:756-766.

Prosen CA, Dore DJ, May BJ (2003) The functional age of hearing loss in a mouse model for presbyacusis. I. Behavioral assessments. Hear Res 183:44-56.

Rubel EW, Fritzsch B (2002) Auditory system development: primary auditory neurons and their targets. Annu Rev Neurosci 25:51-101.

Seidman MD, Ahmad N, Basir U (2002) Molecular mechanisms of agerelated hearing loss. Ageing Res Rev 1:331-343.

Shaywitz AJ, Greenberg ME (1999) CREB: a stimulus-induced transcription factor activated by a diverse array of extracellular signals. Annu Rev Biochem 68:821-861.

Sommer I, Lingenhohl K, Friauf E (1993) Principal cells of the rat medial nucleus of the trapezoid body: an intracellular in vivo study of their physiology and morphology. Exp Brain Res 95:223-239.

Spongr VP, Flood DG, Frisina RD, Salvi RJ (1997) Quantitative measures of hair cell loss in CBA and C57BL/6 mice throughout their life spans. J Acoust Soc Am 101:3546-3553.

von Gersdorff H, Borst JGG (2002) Short-term plasticity at the calyx of Held. Nat Rev Neurosci 3:53-64.

Wang LY, Gan L, Forsythe ID, Kaczmarek LK (1998a) Contribution of the Kv3.1 potassium channel to high-frequency firing in mouse auditory neurons. J Physiol (Lond) 509:183-194.

Wang LY, Gan L, Perney TM, Schwartz I, Kaczmarek LK (1998b) Activation of Kv3.1 channels in neuronal spine-like structures may induce local potassium ion depletion. Proc Natl Acad Sci USA 95:1882-1887.

Weiser M, Bueno E, Sekirnjak C, Martone ME, Baker H, Hillman D, Chen S, Thornhill W, Ellisman M, Rudy B (1995) The potassium channel subunit Kv31b is localized to somatic and axonal membranes of specific populations of CNS neurons. J Neurosci 15:4298-4314.

Willott JF (2001) Handbook of mouse auditory research. Boca Raton, FL: CRC.

Willott JF, Bross LS (1996) Morphological changes in the anteroventral cochlear nucleus that accompany sensorineural hearing loss in DBA/2J and C57BL/6J mice. Brain Res Dev Brain Res 91:218-226.

Willott JF, Bross LS, McFadden SL (1992) Morphology of the dorsal cochlear nucleus in young and aging C57BL/6 and CBA/J mice. J Comp Neurol 321:666-678.

Wisdom R (1999) AP-1: one switch for many signals. Exp Cell Res 253:180185. 